\title{
Glomerulopathy with Homozygous Apolipoprotein E2: A Report of Three Cases and Review of the Literature
}

\author{
Kunio Kawanishi, ${ }^{a}$ Anri Sawada ${ }^{a}$ Ayami Ochi $^{a} \quad$ Takahito Moriyama $^{a}$ \\ Michihiro Mitobe ${ }^{a}$ Toshio Mochizuki ${ }^{a}$ Kazuho Honda ${ }^{b}$ Hideaki Oda $^{b}$ \\ Toshio Nishikawa ${ }^{\text {b }}$ Kosaku Nitta ${ }^{a}$ \\ ${ }^{a}$ Department of Medicine, Kidney Center, and 'Department of Pathology, Tokyo Women's \\ Medical University, Tokyo, Japan
}

\section{Key Words}

Type III hyperlipoproteinemia · Apolipoprotein E2 · Homozygosity · Glomerulopathy · Diabetes

\begin{abstract}
Most cases of type III hyperlipoproteinemia are accounted for by apolipoprotein E2 (apoE2) homozygotes, a genetic mutation of apoE (Arg158Cys). Glomerulopathy with homozygous aPOE2 is rare and characterized by marked foam cell infiltration in the glomerular capillaries and mesangium. Here, we report 3 cases of apoE2 homozygote glomerulopathy diagnosed by renal biopsy and DNA analysis. All 3 cases were middle-aged or elderly males complicated with diabetes for at least a decade. The kidney biopsies showed massive foam cell infiltration in the glomerular capillaries and expanded mesangium accompanied by histological findings of diabetic glomerulosclerosis. The lipid profiles showed type III hyperlipoproteinemia and phenotypic/genetic analyses revealed homozygosity of apoE2. Two of the cases showed nephrotic proteinuria and progressed to renal failure in 3 and 8 years after the diagnosis of kidney disease.

(C) 2013 S. Karger AG, Basel
\end{abstract}

\section{Introduction}

Apolipoprotein E2 (apoE2; Arg158Cys) homozygotes account for more than $90 \%$ of all cases of type III hyperlipoproteinemia (HLP) [1]. Although apoE2 homozygotes comprise

Kunio Kawanishi, MD

Department of Medicine, Kidney Center

Tokyo Women's Medical University

8-1 Kawada-cho, Shinjuku-ku, Tokyo 162-8666 (Japan)

E-Mail KKawa@kc.twmu.ac.jp 
$0.5 \%$ of the Japanese population [2] and $0.6-1 \%$ of the Caucasian population [3], most (95\%) of them are normolipidemic or even hypolipidemic due to low low-density lipoprotein (LDL) cholesterol levels as a result of a compensatory upregulated expression of LDL receptors [1]. Only a minority of apoE2 homozygotes develop type III HLP. The presence of additional genetic, hormonal or environmental factors, such as diabetes mellitus, decreased LDL receptor activity, hypothyroidism, hyperinsulinemia, obesity, menopause, or apoC3 or apoA5 mutations [1, 3], is required for the development of type III HLP. Moreover, glomerulonephropathy in HLP [4,5] or apoE2 homozygotes [6-11], which is characterized by foam cell infiltration in the glomeruli, is very rarely reported, whereas over 100 cases of lipoprotein glomerulopathy (LPG) were found on the PubMed database. LPG is characterized by lipid thrombi in the dilated glomerular capillaries, and patients with LPG are usually harboring various mutations in the $a p o E$ gene [12]. The frequency of apoE2 homozygotes is $0.5-1 \%$ in the general population and may be much higher than the frequency of $a p o E$ variants associated with LPG, such as apoE-Sendai (Arg145Pro), apoE-Kyoto (Cys25Arg) and apoETokyo (Leu141 to Lys143del) [12]. We herein report 3 cases of apoE2 homozygous glomerulopathy diagnosed by renal biopsy and DNA analysis. All 3 patients showed foam cell infiltration in the glomeruli and had a single nucleotide substitution of cysteine for arginine at codon 158 (Arg158Cys) of the apoE gene without other mutations.

\section{Case Report}

Case 1

A 66-year-old male was referred to our center by his primary care physician because of the increase of proteinuria. He was diagnosed with diabetes at the age of 50 years but remained untreated. At the age of 60 years, he started voglibose at the diabetes center of our hospital. At the age of 66 years, urinary abnormality of protein $3+$ and occult blood $1+$ was pointed out, combined with simple diabetic retinopathy and a serum creatinine level of 0.96 $\mathrm{mg} / \mathrm{dl}$. He was referred to our center for further investigation, and a renal biopsy was performed. One of 11 glomeruli showed global sclerosis, and the other glomeruli showed massive foam cell infiltration in the glomerular capillaries and mildly expanded mesangium (fig. 1a). These foam cells immunohistochemically stained positive for cluster differentiation 68 (CD68) (not shown). Transmission electron microscope images also revealed foam cell infiltration mainly located in the capillaries containing scattered lipid droplets and lamellar bodies in their cytoplasm (fig. 1d). The glomerular basement membrane (GBM) showed mild thickening, and nodular lesions were formed in some glomeruli. The interstitium and tubules showed mild fibrosis and atrophy (25\% of the cortical region), and a moderate degree of arteriolar hyalinosis was also found. No interstitial foamy cells or foamy tubular degeneration was found. Immunofluorescence study revealed no significant glomerular deposits. The patient's lipid profile showed type III HLP (table 1). Apolipoprotein phenotype analysis showed a homozygosity of apoE2. A further DNA sequence analysis was performed as described previously [11] and showed a nucleotide substitution of cysteine for arginine at codon 158 (Arg158Cys) of the apoE gene and no other mutations. Eicosapentaenoic acid was added to his statin therapy, but he progressed to end-stage renal failure and was started on dialysis 8 years after the diagnosis.

Case 2

A 58-year-old male was referred to our center by his primary care physician due to nephrotic syndrome. He had massive proteinuria (7.38 g/day) and hypoalbuminemia (1.9 
$\mathrm{g} / \mathrm{dl}$ ). He had been treated for diabetes since the age of 50 years and had been started on insulin therapy at the age of 55 years. He had been well-managed (HbA1c, 5.3\%), although a pre-proliferative retinopathy and mild renal dysfunction $(\mathrm{sCr}, 1.38 \mathrm{mg} / \mathrm{dl}$ ) became evident. His renal biopsy revealed 5 of 22 glomeruli with global sclerosis. The residual glomeruli showed massive foam cell infiltration in the glomerular capillaries and severely widened mesangium (fig. 1b). These foam cells stained positive for CD68 (not shown). Transmission electron microscope images also revealed foam cell infiltration mainly located in the capillaries containing scattered lipid droplets and lamellar bodies in their cytoplasm (fig. 1e). The glomerular tufts were enlarged with hyalinosis, mesangiolysis and microaneurysmal formation, which were consistent with diabetic glomerulosclerosis. The interstitium and tubules showed moderate fibrosis and atrophy (50\% of the cortical region). The foamy change was seen in some tubular epithelial cells, but no interstitial foamy cells were found. The interlobular arteries showed a moderate degree of fibrous intimal thickening, and the arterioles also showed a moderate degree of subendothelial hyalinosis. Immunofluorescence studies revealed nonspecific linear IgG deposits along the GBM; however, no significant deposit was found by electron microscopy. The patient's lipid profile showed type III HLP (table 1). He had an apoE2 homozygote phenotype and the Arg158Cys genotype with no other mutations. Three years after the diagnosis, he progressed to renal failure and was started on hemodialysis.

\section{Case 3}

A 78-year-old male with nephrotic syndrome was referred to our center by his primary care physician. The patient had a history of hypertension since the age of 45 years, hypothyroidism since the age of 68 years and diabetes mellitus since the age of 70 years. He also had a history of percutaneous coronary intervention for coronary artery disease and femoropopliteal bypass surgery for peripheral arterial disease at the age of 74 years, and a history of Wallenberg syndrome since the age of 77 years. He was being treated with an angiotensin II receptor blocker, a calcium-channel blocker, pitavastatin, aspirin and levothyroxine sodium hydrate. Diabetic control by diet and an oral $\alpha$-glucosidase inhibitor were sufficient. There was no evidence of retinopathy or albuminuria before the episode of nephrosis. His urinalysis on admission was positive for proteinuria $(2.5 \mathrm{~g} / \mathrm{day})$ and red blood cells (1-4/hpf). His blood chemistry findings were as follows: albumin $3.2 \mathrm{~g} / \mathrm{dl}$, creatinine $1.11 \mathrm{mg} / \mathrm{dl}$ and HbA1c $6.1 \%$. A kidney biopsy revealed 21 glomeruli, of which 2 were globally sclerotic. The glomeruli showed increased mesangial matrices and mild GBM thickening. Massive foam cells had infiltrated into the glomerular capillaries and mesangial region (fig. 1c, g). These foam cells stained positive with Oil Red 0 (fig. 1h) and immunohistochemically stained positive for CD68 (fig. 1i). Transmission electron microscope images also revealed foam cell infiltration mainly located in the capillaries, and some mesangial cells showed scattered lipid droplets in their cytoplasm (fig. 1f). Mild interstitial fibrosis and tubular atrophy (20\% of the cortical region) as well as moderate arteriosclerosis and arteriolar hyalinosis were found. The foamy change was seen in some tubular epithelial cells but no interstitial foamy cells were found. Immunofluorescence studies revealed segmental deposits of IgM and C3 in the mesangial area and slightly peripheral IgG deposits in the glomeruli; however, no significant deposit was found by electron microscopy. He had an apoE2 homozygote phenotype and the Arg158Cys genotype with no other mutations. After the diagnosis, ezetimibe was added to his statin therapy. The patient's most recent serum creatinine was increased to $2.1 \mathrm{mg} / \mathrm{dl}$ after 2 years. 


\section{Discussion}

Here, we report 3 cases of glomerulopathy with apoE2 homozygosity. All 3 cases were 58- to 78-year-old elderly males with an at least 10-year history of diabetes. Their renal biopsies showed remarkable foam cell infiltration in the glomeruli accompanied with various degrees of glomerular abnormalities indicating diabetic nephropathy (DMN), such as mesangial expansion, GBM thickening, and nodular lesion formation. As glomerular foam cell infiltration is sometimes seen in DMN, it is difficult to differentiate between glomerulopathy with homozygous apoE2 (apoE2/2) and DMN completely. However, the degree of foam cell infiltration in each case was unusually remarkable compared to that of ordinary DMN. The 3 cases had the apoE2 homozygote phenotype and Arg158Cys genotype with no other mutations in common. Only 7 cases of glomerulopathy with apoE2 homozygosity have been reported previously [6-11], whereas over 100 cases of LPG have been reported (table 2). All 7 cases showed nephrotic syndrome clinically, and 2 of them had diabetes [6,9]. The fact that all of our 3 cases were elderly and had a 10-year history of diabetes suggests a possible role for diabetes in the development of apoE2 homozygote glomerulopathy. However, what factors in the patients induced type III HLP or glomerular foam cell infiltration remains undetermined.

The histology of apoE2 homozygote glomerulopathy is characterized by marked glomerular foam cell infiltration and is different from that of LPG, which shows lipoprotein thrombi with lamella formation in dilated glomerular capillaries. LPG seldom presents with massive foam cells infiltration in the glomeruli. One unusual case with LPG, a 54-year-old Japanese female, showed an apoE2 homozygote phenotype [13]. In this case, the details of microscopic lamella formation in the lipid thrombi were unclear [13]. On the other hand, a previous report of siblings with apoE2 homozygote glomerulopathy showed an unusual finding of glomerular lipoprotein thrombi and lipid particles [11]. The lamella formation in the lipid thrombi could not be detected on the electron microscopic images, however, suggesting that the ultrastructure of the lipid droplets in apoE2 homozygote glomerulopathy is different from that in LPG. Regarding lipid-lowering treatment, 5 of the 7 previous cases were treated with fibrate [6-11]. In our 3 cases, ezetimibe or eicosapentaenoic acid was combined with their ongoing statin therapies. The selection of these drugs was supported by the evidence that additional fibrate use in elderly people can be associated with serum creatinine elevation [14]. Conversely, repeated plasmapheresis using a dextran sulfatecellulose column was effective in reducing proteinuria in a 59-year-old female with apoE2 homozygote glomerulopathy [6].

Concerning renal prognosis, prednisolone, FK-506 or cyclophosphamide could not prevent renal failure in a 12-year-old boy [8]; however, a 52-year-old male maintained normal renal function for 10 years despite massive proteinuria [11]. In 2 of our 3 cases, renal failure progressed 3 and 8 years after the diagnosis of kidney disease, and the third case also showed a gradual elevation of serum creatinine during the 2-year follow-up.

Etiologically, apoE2 homozygosity and the other apoE mutations may be responsible for the development of the unique glomerulopathy both in LPG and apoE2 homozygote glomerulopathy. Patients with the apoE2 homozygote phenotype also presented the glomerular lesions of LPG [13] or LPG-like lesions [11]. Similarly, the coexistence of homozygous apoE2 and heterozygous apoE variants, such as apoE-Okayama (Arg150Gly) [15] and apoE-Modena (Arg150Cys) [16], has been reported in some cases with LPG. These reports are suggesting that a single mutation of $a p o E$, or a combination of a certain $a p o E$ mutation and homozygous apoE2, may induce the functional abnormality of apoE synergistically and result in the unique form of lipid-related glomerulopathy, such as LPG and apoE2 
homozygote glomerulopathy. Moreover, our cases are suggesting that diabetes is another contributing factor for the development of glomerulopathy. A previous report [17], showing apoE2 as a risk factor for the progression of DMN in Japanese type 2 diabetes, also indicates a close association between DMN and lipid-related glomerulopathy.

In conclusion, apoE2 homozygote glomerulopathy occurred in combination with DMN in our 3 elderly cases. We speculate that macrophage and lipid in addition to diabetes play a role in this unique lipid-related glomerulopathy. Further investigations are required to determine the pathogenesis of apoE2 homozygote glomerulopathy and the clinical evidences for an appropriate therapeutic strategy.

\section{Acknowledgements}

We thank Shigeru Horita, Hideki Nakayama, and Mayuko Ohno for their technical support.

\section{Disclosure Statement}

The authors have no conflicts of interest to declare.

\section{References}

$>1$ Mahley RW, Huang Y, Rall SC: Pathogenesis of type III hyperlipoproteinemia (dysbetalipoproteinemia). Questions, quandaries, and paradoxes. J Lipid Res 1999;40:1933-1949.

-2 Eto M, Saito M, Nakata H, Iwashima Y, Watanabe K, Ikoda A, Kaku K: Type III hyperlipoproteinema with apolipoprotein E2/2 genotype in Japan. Clin Genet 2002;61:416-422.

-3 Henneman P, van der Sman-de Beer F, Moghaddam PH, Huijts P, Stalenhoef AF, Kastelein JJ, van Duijn CM, Havekes LM, Frants RR, van Dijk KW, Smelt AH: The expression of type III hyperlipoproteinemia: involvement of lipolysis genes. Eur J Hum Genet 2009;17:620-628.

4 McKenzie IF, Kincaid-Smith P: Foam cells in the renal glomerulus. J Pathol 1969;97:151-154.

5 Amatruda JM, Margolis S, Hutchins GM: Type 3 hyperlipoproteinemia with mesangial foam cells in renal glomeruli. Arch Pathol 1974;98:51-54.

6 Suzaki K, Kobori S, Ueno S, et al: Effects of plasmapheresis on familial type III hyperlipoproteinemia associated with glomerular lipidosis, nephrotic syndrome and diabetes mellitus. Atherosclerosis 1990;80:181-189.

7 Ongkingco JR, Mann WA, Ruley EJ, Gregg RE: Severe hyperlipidemia due to multiple factors in a child with nephrotic syndrome. Child Nephrol Urol 1991;11:107-110.

-8 Ellis D, Orchard TJ, Lombardozzi S, Yunis EJ, McCauley J, Agostini R, Diamond JR: Atypical hyperlipidemia and nephropathy associated with apolipoprotein E homozygosity. J Am Soc Nephrol 1995;6:1170-1177.

-9 Balson KR, Niall JF, Best JD: Glomerular lipid deposition and proteinuria in a patient with familial dysbetalipoproteinaemia. J Intern Med 1996;240:157-159.

$\$ 10$ Joven J, Vilella E: The influence of apoprotein epsilon 2 homozygosity on nephrotic hyperlipidemia. Clin Nephrol 1997;48:141-145.

11 Sakatsume M, Kadomura M, Sakata I, Imai N, Kondo D, Osawa Y, Shimada H, Ueno M, Miida T, Nishi S, Arakawa M, Gejyo F: Novel glomerular lipoprotein deposits associated with apolipoprotein E2 homozygosity. Kidney Int 2001;59:1911-1918.

12 Saito T, Matsunaga A, Oikawa S: Impact of lipoprotein glomerulopathy on the relationship between lipids and renal diseases. Am J Kidney Dis 2006;47:199-211.

13 Amenomori M, Haneda M, Morikawa J, Nishigaki I, Maeda S, Hidaka H, Kikkawa R, Shigeta Y: A case of lipoprotein glomerulopathy successfully treated with probucol. Nephron 1994;67:109-113.

14 Zhao YY, Weir MA, Manno M, Cordy P, Gomes T, Hackam DG, Juurlink DN, Mamdani M, Moist L, Parikh CR, Paterson JM, Wald R, Yao Z, Garg AX: New fibrate use and acute renal outcomes in elderly adults: a population-based study. Ann Intern Med 2012;156:560-569. 
Kawanishi et al:: Glomerulopathy with Homozygous Apolipoprotein E2: A Report of

15 Kinomura M, Sugiyama H, Saito T, Matsunaga A, Sada KE, Kanzaki M, Takazawa Y, Maeshima Y, Yanai H, Makino H: A novel variant apolipoprotein E Okayama in a patient with lipoprotein glomerulopathy. Nephrol Dial Transplant 2008;23:751-756.

-16 Cautero N, Di Benedetto F, De Ruvo N, et al: Novel genetic mutation in apolipoprotein E2 homozygosis and its implication in organ donation: a case report. Transplant Proc 2010;42:1349-1351.

17 Araki S, Koya D, Makiishi T, Sugimoto T, Isono M, Kikkawa R, Kashiwagi A, Haneda M: APOE polymorphism and the progression of diabetic nephropathy in Japanese subjects with type 2 diabetes: results of a prospective observational follow-up study. Diabetes Care 2003;26:2416-2420.

Table 1. Examinations at the time of admission

\begin{tabular}{llll}
\hline & Case 1 & Case 2 & Case 3 \\
\hline Age, years & 66 & 58 & 78 \\
Sex & male & male & male \\
Urinary protein, g/day & 2.07 & 7.38 & 2.5 \\
Total protein, g/dl & 6.4 & 3.9 & 6 \\
Albumin, g/dl & 3.5 & 1.9 & 3.6 \\
Serum creatinine, mg/dl & 0.96 & 1.38 & 1.11 \\
HbA1c, \% & 6.9 & 5.3 & 6.1 \\
Total cholesterol, mg/dl & 221 & 253 & 287 \\
Triglyceride, mg/dl & 437 & 194 & 389 \\
Lipoprotein electrophoresis, \% & & & \\
$\quad$ HDL (22-47) & 20.3 & 14.4 & 27 \\
$\quad$ LDL (46-68) & 7.4 & 20.2 & 8 \\
$\quad$ IDL (0) & 46 & 41.5 & 46 \\
$\quad$ VLDL (3-19) & 26.3 & 23.9 & 19 \\
Apolipoproteins, mg/dla & & & \\
$\quad$ ApoA (119-155) & 92 & 112 & 156 \\
$\quad$ ApoB (7-109) & 74 & 79 & 65 \\
$\quad$ ApoE (2.7-4.3) & 11.4 & 10.7 & 9.9 \\
\hline
\end{tabular}

a Normal ranges for males are given in parentheses. 


DOI: $10.1159 / 000356849$

C 2013 S. Karger AG, Basel

www.karger.com/cru

Kawanishi et al.: Glomerulopathy with Homozygous Apolipoprotein E2: A Report of

Three Cases and Review of the Literature

Table 2. Features of glomerulopathy with homozygous apoE2

\begin{tabular}{|c|c|c|c|c|c|c|c|c|c|}
\hline $\begin{array}{l}\text { Patient } \\
\text { No. }\end{array}$ & Sex & $\begin{array}{l}\text { Age, } \\
\text { years }\end{array}$ & $\begin{array}{l}\text { Protein- } \\
\text { uria, g/day }\end{array}$ & $\begin{array}{l}\mathrm{sCr} \text { at diagnosis, } \\
\mathrm{mg} / \mathrm{dl}\end{array}$ & Complications & Therapy & $\begin{array}{l}\text { Renal prognosis } \\
\text { after diagnosis }\end{array}$ & $\begin{array}{l}\text { Athero- } \\
\text { sclerosis }\end{array}$ & Ref. \\
\hline 1 & $\mathrm{~F}$ & 59 & $0.6-8.8$ & 1.8 & DM, HT & $\begin{array}{l}\text { fibrate, colestyramine, } \\
\text { plasmapheresis }\end{array}$ & $\begin{array}{l}\mathrm{sCr} 2.2 \mathrm{mg} / \mathrm{dl} \\
2.5 \text { years later }\end{array}$ & none & 6 \\
\hline 2 & $\mathrm{~F}$ & 0 & $3+$ to $4+$ & 0.3 & ND & $\begin{array}{l}\text { PSL, furosemide, } \\
\text { metolazone }\end{array}$ & $\begin{array}{l}\mathrm{sCr} 4.2 \mathrm{mg} / \mathrm{dl} \\
7.5 \text { years later }\end{array}$ & none & 7 \\
\hline 3 & M & 12 & 20.3 & 1.1 & anemia & $\begin{array}{l}\text { RASI, PSL, CY, FK-506, } \\
\text { statin } \rightarrow \text { fibrate }\end{array}$ & $\begin{array}{l}\text { renal failure } \\
1.3 \text { years later }\end{array}$ & none & 8 \\
\hline 4 & M & 31 & $1.8-4.5$ & 1.2 & $\begin{array}{l}\text { DM, pan- } \\
\text { creatitis }\end{array}$ & fibrate $\rightarrow$ statin & ND & none & 9 \\
\hline 5 & M & 41 & $2.8-18.4$ & NR & none & PSL, CY, statin and fibrate & $\begin{array}{l}\text { no progression } \\
0.7 \text { years later }\end{array}$ & none & 10 \\
\hline 6 & M & 52 & $3.0-7.5$ & 0.8 & none & PSL, aspirin & $\begin{array}{l}\text { no progression } \\
\text { for } 10 \text { years }\end{array}$ & none & 11 \\
\hline 7 & $\mathrm{~F}$ & 49 & $2.0-4.0$ & 0.5 & HT & fibrate & $\begin{array}{l}\text { no progression } \\
\text { for } 2 \text { years }\end{array}$ & none & 11 \\
\hline 8 & M & 64 & $1.6-2.1$ & 0.9 & DM & RASI, statin, EPA & $\begin{array}{l}\text { HD induction } \\
8 \text { years later }\end{array}$ & CAD & $*$ \\
\hline 9 & M & 58 & $5.0-8.8$ & 1.6 & DM, HT & RASI, statin, EPA & $\begin{array}{l}\text { HD induction } \\
3 \text { years later }\end{array}$ & none & $*$ \\
\hline 10 & M & 78 & $1.9-4.2$ & 1.1 & $\begin{array}{l}\text { DM, HT, } \\
\text { hypothyroidism }\end{array}$ & RSI, statin, ezetimibe & $\begin{array}{l}\text { sCR } 2.1 \mathrm{mg} / \mathrm{dl} \\
2 \text { years later }\end{array}$ & $\begin{array}{l}\text { CAD, CI, } \\
\text { PAD }\end{array}$ & $*$ \\
\hline
\end{tabular}

$\mathrm{CAD}=$ Coronary artery disease $\mathrm{CI}=$ cerebral infarction; $\mathrm{CY}=$ cyclophosphamide; $\mathrm{DM}=$ diabetic mellitus; $\mathrm{EPA}=$ eicosapentaenoic acid; $\mathrm{HD}=$ hemodialysis; $\mathrm{HT}=$ hypertension; $\mathrm{ND}=$ not described; $\mathrm{NR}=$ within the normal range; $\mathrm{PAD}=$ peripheral arterial disease; $\mathrm{PSL}=$ prednisolone; RASI = renin-angiotensin system inhibitor; $\mathrm{sCr}=$ serum creatinine. ${ }^{*}$ Current cases. 
Kawanishi et al.: Glomerulopathy with Homozygous Apolipoprotein E2: A Report of Three Cases and Review of the Literature
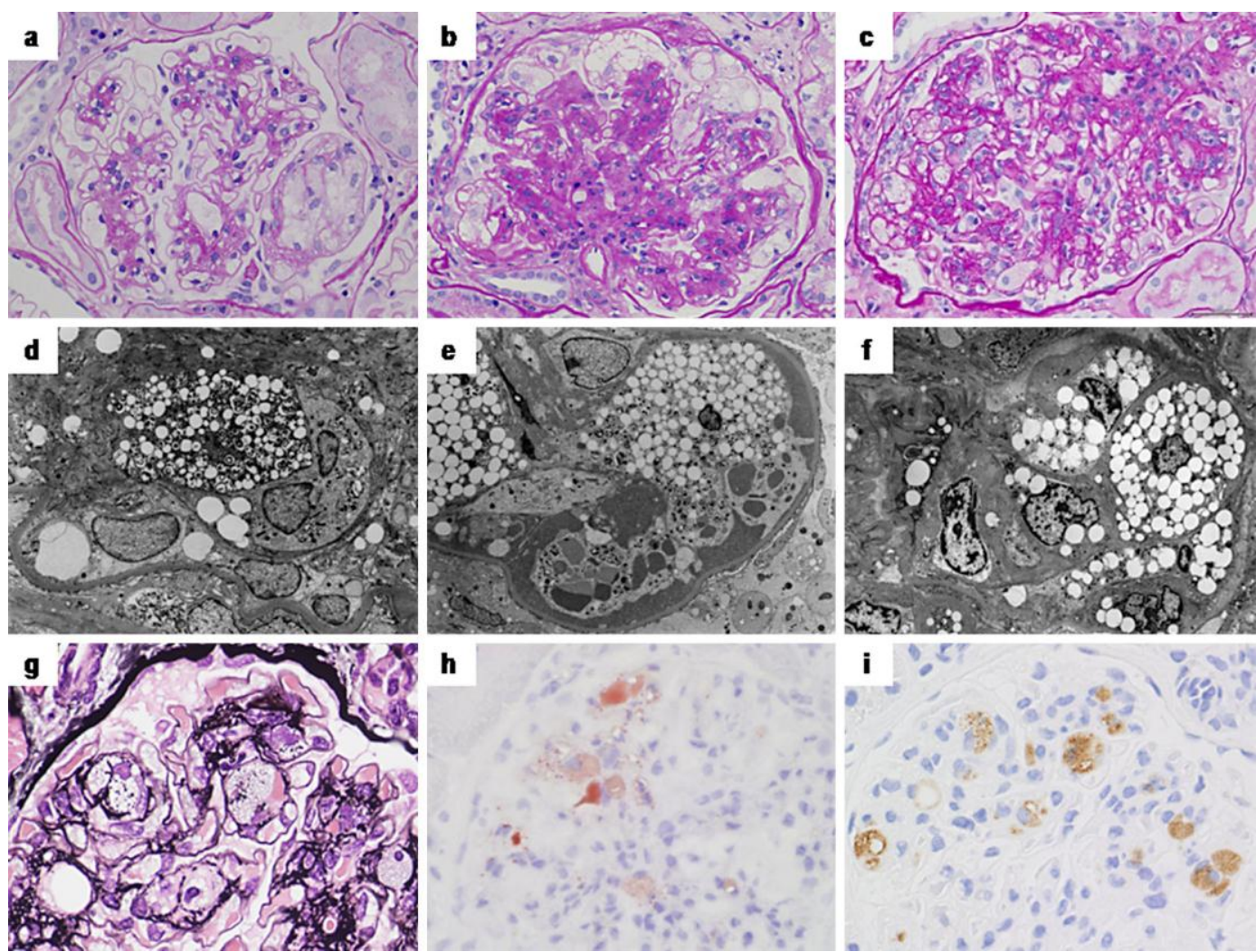

$\mathbf{h}$
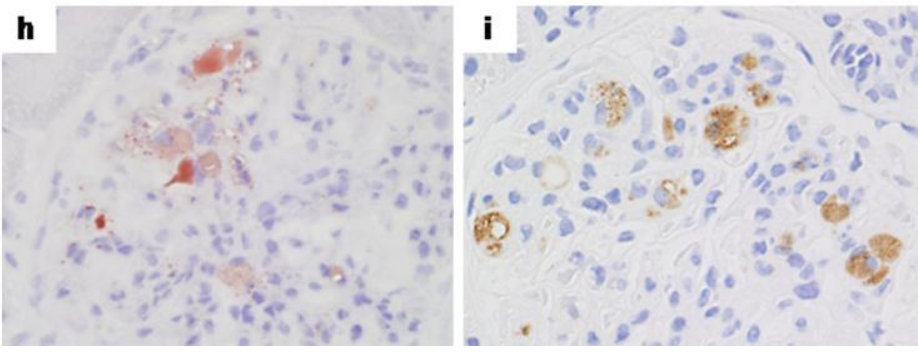

Fig. 1. Light and electron microscopic findings of the renal biopsy specimens. The glomeruli show massive foam cell infiltration mainly in the glomerular capillaries and partly in the mesangium (a-g). The foam cells are stained positive with Oil Red $\mathrm{O}(\mathrm{h})$ and are positive for CD68 by immunohistochemistry (i). Transmission electron microscope images reveal foam cells with lipid droplets or lamellar bodies mainly located in the capillaries (d-f), and some mesangial cells show scattered lipid droplets in their cytoplasm (f). Magnification in $\mathbf{b}, \mathbf{d}, \mathbf{f}: \times 2,000$. Signs for diabetic glomerulosclerosis, such as an increase of mesangial matrices (b > a, c) and a thickening of the GBM, could be found to various degrees. a, $\mathbf{d}$ Case 1; b, e case 2; $\mathbf{c}$, $\mathbf{f}-\mathbf{i}$ case 3 . 